\title{
Linguistic Identities in the Digital Space
}

\author{
Enikő BIRÓ \\ Sapientia Hungarian University of Transylvania (Cluj-Napoca, Romania) \\ Department of Applied Linguistics, Târgu-Mureş \\ biro.eniko@ms.sapientia.ro
}

\begin{abstract}
Within the digital world, new multilingual contacts appeared, which led to a more multilingual Web and enabled local and global participation that assert new identities (Lenihan and Kelly-Holmes 2017). For multilingual people, language choice and code-switching serves as a means for users to perform a specific image of cultural or personal identity and signal their affiliation with a particular community. The paper analyses digital multilingual practices of bilingual (Hungarian-Romanian) university students in Romania. The data consists of students' public Facebook profiles, examining language choice, code-switching, and hybrid practices. My research question refers to how their linguistic identity is constructed in their online communicative practices. Multilingual practices in the social media are not necessarily connected to language competences in a traditional sense and may serve as a space for resolving conflicting linguistic identities. In my data, students use their diverse linguistic and semiotic resources in varying ways to express and build their online identity, relying on the multimodal affordances of the digital world. Online multilingual practices rely on the speaker's complete language repertoire, but they do not necessarily depend on language proficiency.
\end{abstract}

Keywords: digital, linguistic repertoire, identity, code-switching

\section{Introduction}

The paper investigates digital linguistic practices of bilingual university students at Sapientia Hungarian University of Transylvania (henceforth: Sapientia), examining how the digital world enables multilingual encounters and crosslanguage relations, where multilingualism includes the combination of separate languages and facilitates hybrid practices. Social media provides multimodal resources for the expression of users' identities, where images, videos, written and spoken languages are combined. Social media users creatively adopt linguistic resources and use their linguistic repertoires to construct their online linguistic 
identity, which may differ from their offline linguistic identities, especially in the case of people with an ethnic minority background. Identity, in my approach, "is constituted in and through language, and we use language to articulate ideas and to represent ourselves and our social relations" (Darvin 2016: 523).

The possibilities of the social media and the use of multimodality in the digital world have undoubtedly increased the diversity of linguistic practices. The construction of the self-image is an important part of social media, and language plays a major role in it. Recently, there has been an increase in research on identity construction in digital spaces. Most findings "generally conceptualize students' linguistic identities as fluid and dynamic and treat linguistic identities as fixed to particular languages; (...) so multilingual writers deliberately switch between languages in order to communicate with different audiences or display aspects of their identities" (Schreiber 2015: 70). However, the "division of identities by first and second (and third and fourth) languages seems insufficient to explain the intricate intermingling of language resources so evident in online spaces" (Schreiber 2015: 70). Users have "the ability of multilingual speakers to shuttle between languages, treating the diverse languages that form their repertoires as an integrated system" (Canagarajah 2011: 401). On the other hand, the dynamics of multilingual users' digital linguistic practices and identity constructions in social networking communities are still unclear.

The purpose of this paper is to examine students' use of online linguistic repertoires and linguistic/semiotic resources on Facebook and to examine their multi-language-mediated identity. My research question focuses on how linguistic identity is constructed through the multilingual and multimodal nature of online communication and whether the digital space may serve as a territory for resolving conflicting linguistic identities in the case of minority speakers. Adopting a qualitative approach of blended data method (Androutsopoulos 2013), this paper explores the relationship between the overall linguistic background of the students, online linguistic repertoires, categories of code-switching and hybrid practices, and the students' explanations of their digital linguistic identities.

The article is structured as follows: after adapting the definition of ethnic identity, linguistic identity, and linguistic repertoire to the analysis, the biographical context, where language choice and different language practices take place, is presented, followed by the introduction of the context. The context refers to the linguistic background of the participants: bilingual minority speakers and language learners at Sapientia University will be discussed, followed by a description of the methodology and data. The findings, conclusions, and, finally, the suggestions for further research to extend the boundaries of digital linguistic repertoire are discussed. 


\section{Theoretical background. Linguistic identity, multilingualism, and linguistic repertoire}

In the last decade, there has been an increase in the use of the social media platforms. Facebook has become one of the most popular social media sites. As such, it provides a rich source of linguistic data analysis as technology has transformed the world and language use in unanticipated ways. Human generations have seen a huge growth in the development of technology. However, different generations have experienced the technological evolution in different ways. Generation X, as a label, is given to those who were born between 1960 and 1980, the time period just before technology invaded our lives (McCrindle and Wolfinger 2009). Millennials, or Generation Y, mean the generation which belongs to the time period from 1982 to 2000, and Generation Z, born after 1995, include the mostly tech savvy and inclusive people. Generation X uses social media on a monthly basis. The gap is not dramatic between generations $\mathrm{X}$ and $\mathrm{Y}$. The members of generation $\mathrm{Y}$ rely on their smartphones to perform a number of practical functions. Generation $\mathrm{Z}$ are truly digital natives who spend more time online than any previous generation (Hayes et al. 2015). With the birth of the next generation, the alpha generation, changes will be even more radical in the use of digital literacy.

These changes have already affected the presentation of users' identities as the social media provide opportunities for a wide range of multimodal resources to construct identities online (Darvin 2016). Users of the social media are able to present different aspects of identity through language choice. Bilingual undergraduate students, as participants of the present study, are able to deploy their multiple linguistic resources as well. These resources include not only the various spoken and written languages available to them but also the textmaking strategies they adopt in online communication. Therefore, we need to reconsider conceptions of linguistic identity based on how students understand language use and identity in the digital space and what it might mean to have a multilingual identity online.

Ethnic identity is an ethnic group's sense of belonging to a specific group. Identification of ethnic minority groups includes many different markers of identity, and language choice is one of the most important ones. Linguistic identity plays a significant part in the formation of ethnic identity (Lenihan and Kelly-Holmes 2017). Linguistic identity means associating yourself with a specific language. The choice and use of language or languages obviously depend on the speakers, the activity, the topic, etc. Language environment is an important factor in the case of linguistic identity because everything that influences the language environment also influences the individual and their language use.

Traditional approaches describe multilingualism from an additive point of view, where each language used by the speaker is seen as a separate system. The 
new approaches in the post-multilingualism (Li 2016) era define multilingualism as "a complex of specific semiotic resources" (Blommaert 2016). Gorter and Cenoz (2017) propose a holistic approach to multilingualism: focusing on the linguistic repertoire to describe how speakers use their linguistic repertoires in their social networks. These new concepts raise fundamental questions about what language is in everyday social interactions and become even more complex in the case of digital discourses as social interactions. Online users rely on diverse linguistic resources and combine the use of linguistic and semiotic resources, and social media networks (such as Facebook) become appropriate spaces to provide multimodality. These online resources and repertoires of languages contribute to the construction of linguistic identity together with the offline, ethnic linguistic identity of the users. The creative use of the users' linguistic repertoire is particularly evident in the digital space. Linguistic repertoire, therefore, can be defined as "a shift away from structure, system, and regularity toward approaches that acknowledge fluidity and creativity in linguistic practices" (Busch 2012).

This research focuses on different types of linguistic practices, based on the linguistic repertoires and semiotic resources of the participants, mostly on code-switching and hybrid practices in online social media, which support and shape identity construction and provide multiple choices of language use, multimodality, and intertextuality, which are crucial parts of the construction of the identity (Darvin 2016). Online social media, such as Facebook, promotes multilingual creativity, manifested in code-switching and hybrid practices.

Initially, code-switching was viewed as a product of local speech community identities and then as contrastive nation-state identities (Hall and Nilep 2015: 598); however, the new approaches focus on code-switching as "language choice controlled by pre-existing indexical ties to identities (...) as a resource in urban minority communities for the performance of multicultural and interethnic identities", and, moreover, "hybrid identities" (Hall and Nilep 2015: 611). Recent studies focus on hybrid identities, which - according to Hall and Nilep (2015) refer to the image or self-image of people at national and linguistic margins, and social interaction materializes in a discourse which becomes normative. These views depart from the "either-or" choice between two languages and turn us towards a multilingual repertoire (Hall and Nilep 2016: 608). Hybrid practices, in this study, refer to language mixing, and, as Canagarajah (2013) points out, different types and degrees of language mixing are encouraged in digital communication, in the digital space. The meaning of these hybrid practices might indicate an individual or group identity. 


\section{Linguistic background of the research. Hungarian ethnic minority, bilingual students}

The research presented in this paper investigates the digital linguistic identity of the study participants: undergraduate bilingual students of Sapientia. The majority of the students come from the three counties of Romania where Hungarians comprise the majority of the population: Covasna, Harghita, and Mureş counties. Individual bilingualism, ${ }^{1}$ defined by Skutnabb-Kangas and McCarty (2008: 4-5), is applied to indicate different levels of the participants' L2 proficiency. Individual bilingualism marks an individual's use of two or more languages. Throughout this paper, the term first language (L1) is used to refer to Hungarian as the language "best known and/or most used" by the speakers in question and, in most cases, the language self-identified with and also by other people as the "native language", or "mother tongue", and contrasted with L2, the second language (Skutnabb-Kangas and McCarty 2008: 6). In our case, L2 is Romanian. All the participants of this study have learnt English as a foreign language; therefore, L3 refers to English throughout this paper.

When offline, most of the participants characterize themselves as Hungarian dominant bilinguals, except for those who come from bilingual (HungarianRomanian) families, therefore, growing up as more balanced bilinguals with a chance to choose a Romanian linguistic identity and get accepted as a native Romanian speaker by others as well. When online, e.g. when users post status updates on their Facebook profiles, they generally address a broader audience, which might include people from different linguistic backgrounds. As such, language choice depends not only on the content of the status update but also on the imagined or intended audience. Likewise, the use of one particular language or variety may indicate the selection of a particular group within the network. Similarly, the comments can prompt a variety of linguistic choices depending on the linguistic repertoire of the participants. Although an initial post or comment may appear in one particular language, the comment writers who are engaged in the discourse may opt to switch to (an)other language(s). Thus, language choice becomes an important strategy for audience design. The use of Romanian can be avoided by Hungarian dominant bilinguals who live in a mostly monolingual offline environment; these users might prefer a more monolingual Facebook profile, according to my observations.

1 Individual bi-/multilingualism, sometimes called plurilingualism, involves proficiency in and use of two or more languages by an individual. The term used by the authors does not always imply an equally high level of proficiency in all the relevant languages (Skutnabb-Kangas and McCarty 2008). 


\section{Study design, methodology, and data collection}

The linguistic repertoire of a group or an individual cannot be grasped solely by observing interactions within the group, analysing online discourses. The observation of multilingual practices has to be combined with metalinguistic commentaries by participants, gained through interviews and group discussions. As a methodological framework we intend to use the blended data ${ }^{2}$ method defined by Androutsopoulos (2013: 240). To achieve a deep understanding, there is a need to adopt a highly contextualized approach to present the overall linguistic background of the students, online linguistic repertoires, categories of code-switching and code-mixing, and the students' explanations of their digital linguistic behaviour and use. The blended data method involves observing the participants' language use online and also having close contact with them in the form of semi-structured interviews and group discussions.

Three phases of data collections were carried out in our study. The first phase aimed to collect demographic information about the participants as well as linguistic data with the help of snapshots of the "publicly-private" ${ }^{3}$ Facebook profiles. Later on, these data were analysed and categorized according to the participants' language choice and linguistic practices. The content analysis revealed different patterns of linguistic practices used in status updates, captions (profile pictures, cover photos, etc.), comments, and hashtags. This first phase of the study served as a basis for designing the group discussion and interview protocol in the next two phases. Linguistic data collection was followed by focus group discussions with two groups made up of 18-20 students. The participants of these groups filled out a questionnaire, where questions referred to their language use on Facebook and their opinion regarding language use and choice of fellow Facebook users as well: i.e. Facebook language (setting); language choice for posts, comments; use of multiple languages; mix of languages within one comment or caption, etc.

The interviews, as the third phase of the data collection, focused largely on the four interview participants' metalinguistic commentaries referring to their social media language use and language choice.

The data collection was completed between January and April 2019. $1^{\text {st }}, 2^{\text {nd }}$ and $3^{\text {rd }}$-year Sapientia University undergraduates participated in the study. Their age ranged between 19 and 30. Table 1 presents the distribution of participants according to their studies. The participants included Agricultural Engineering

2 According to Androutsopoulos (2013), blended data refers to the combination of online data and data collection through direct contact with selected users, where user-based data will complement the analysis of online data.

3 "Publicly private" means people may share their lives in a "publicly private" manner (Lange 2007), that is, where the identity of the content poster is revealed but access to the content posted is relatively controlled. 
students (pursuing studies in Sfântu Gheorghe) and students majoring in Translating and Interpreting as well as Communication and Public Relations (Târgu-Mureş).

No. of students

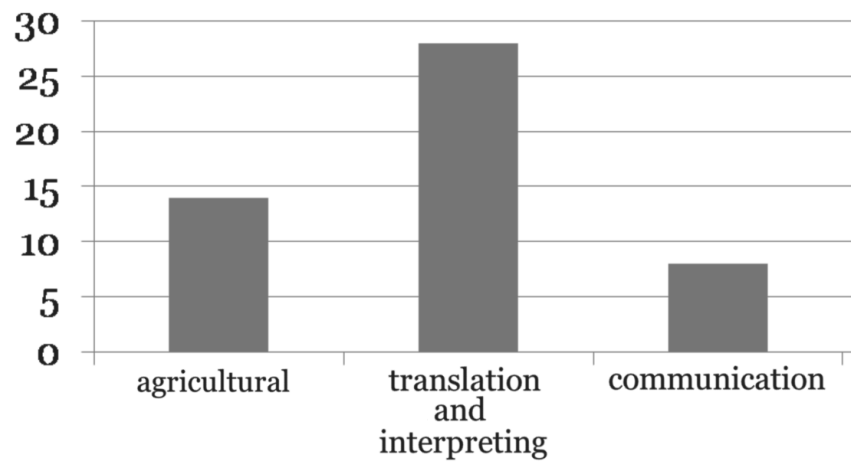

Table 1. Number of participants based on their studies at Sapientia

All participants met these selection criteria:

- they are Hungarian dominant bilingual speakers with various proficiency levels of L2 (Romanian),

- they also use English as their L3 to some degree,

- they also learnt further languages during their studies.

\section{Discussion of language choice and linguistic practices as identity construction processes}

The participants of the research belong to the $\mathrm{Y}$ and $\mathrm{Z}$ generations, who rely on their smartphones and use the digital space to interact. The digital space is a multilingual space with the affordance of multilingual practices. However, these generations grew up with the linguistic ideologies of the ethnic minority community, and the "one language-one nation" linguistic ideology relies on the preservation and protection of the minority language (Lanstyák 2011). According to the present study observations, the $\mathrm{X}$ generation, the parents of the participants of the research, expect the next generations to follow similar language choices to express the same linguistic identity that may characterize their offline linguistic identities as well. As an example, a member of the older generation commented in Hungarian on his son's cover photo update, which was written by the son in English. The father's comment: "Write in Hungarian ... you live in Transylvania, son!" emphasizes the expected (monolingual) linguistic identity in the minority community. This linguistic identity should not be different whether they 
communicate online or offline. However, with a multilingual linguistic repertoire, the speakers' online linguistic identity appears to be more diverse, fluid, and complex. In the digital space, users are able to perform multiple identities with the mobilization of linguistic resources and with the help of a rich mix of semiotic modes. The majority of the study participants use Hungarian (L1) as the default language of their Facebook profiles, followed by English (L3) and Romanian (L2). The details of patterns of language choice, code-switching, and hybrid practices are revealed by content analysis within the following Facebook features.

\section{A. Timeline profile intro or status updates}

Language choice for profile intro or status updates depends not only on the content of the status update but also on the imagined audience for whom the status update is designed.

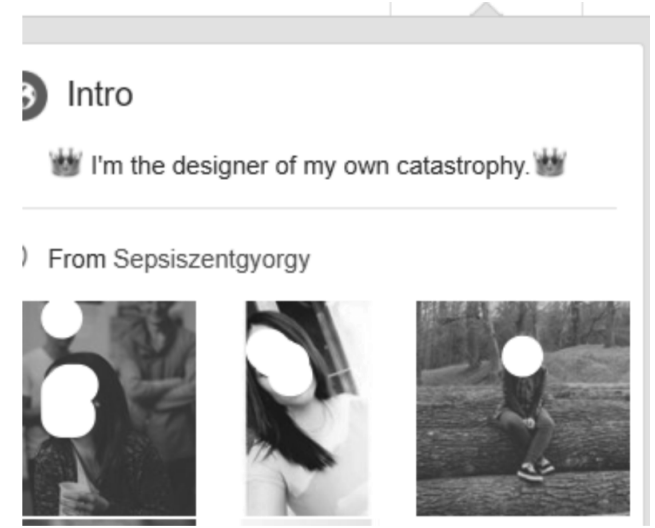

Figure 1. Hungarian dominant bilingual student writing their Intro in English

Timeline is the original profile space where Facebook users' content is displayed. It allows the posting of messages, often short or temporal notes, which are visible to anyone. A user's most recent updates appear at the top of their Timeline. According to the study data, most of the participants use Hungarian. Multimodality is the key; photos and gifs accompany these updates. The use of English addresses a global audience and becomes the element of self-fashioning. ${ }^{4}$ English is often used in the case of cover photos and profile pictures. Users shuttle between languages, treating the diverse languages that form their repertoire as an integrated system.

4 The term originally was introduced by Stephen Greenblatt (Renaissance Self-Fashioning, 1980) and used to describe the process of constructing one's identity and public persona according to a set of socially acceptable standards; here we use it to describe the process of constructing one's linguistic identity according to a set of multilingual standards. 


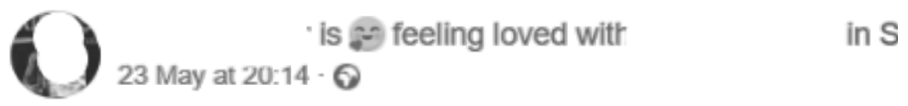

The best momy in the world..I miss u so much

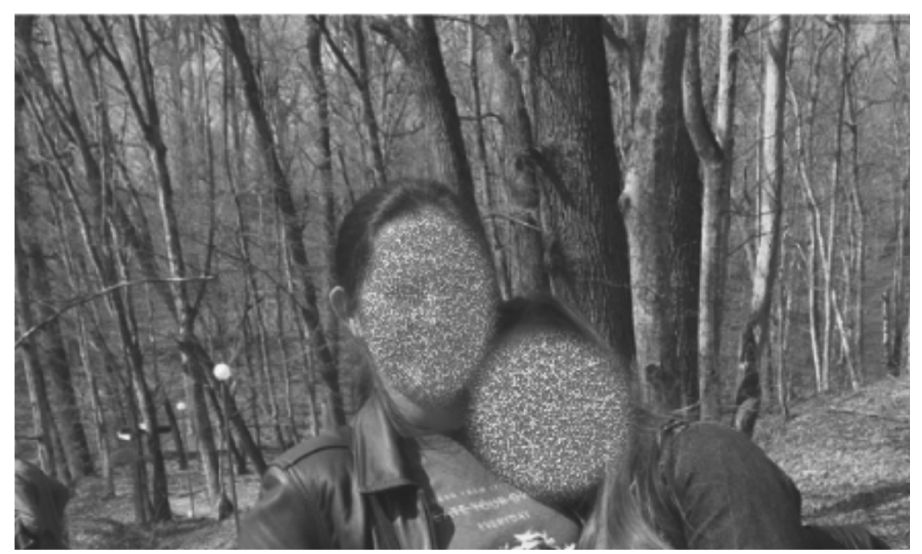

Figure 2. Hungarian dominant bilingual student updating her cover photo in English.
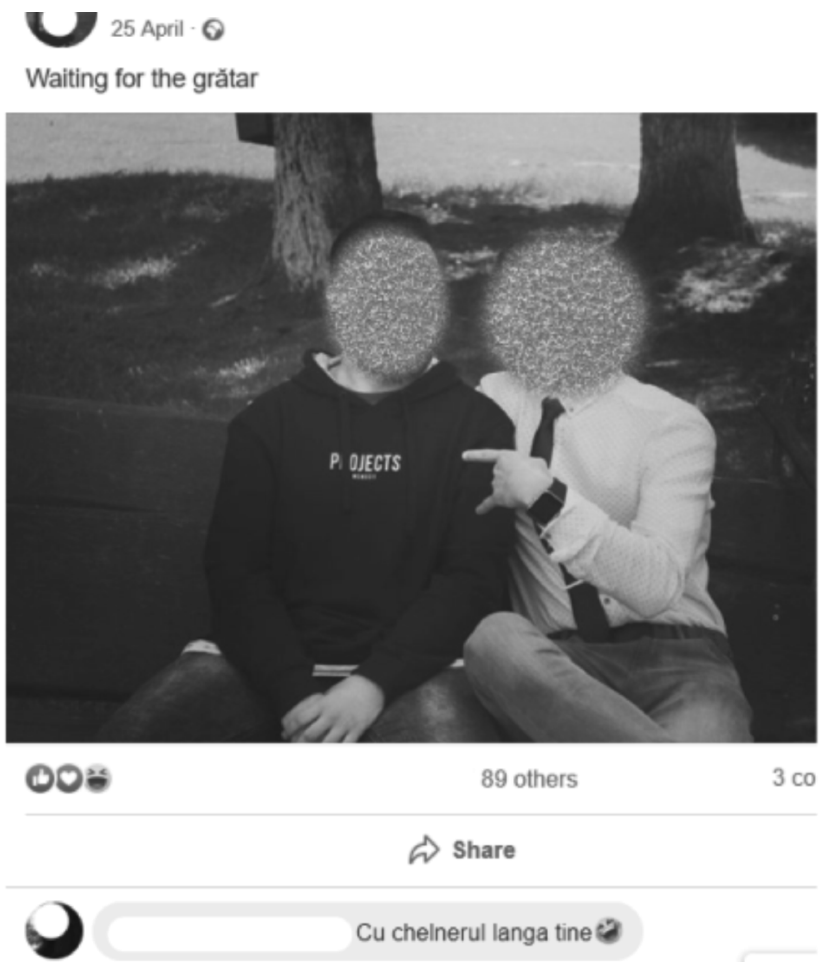

Figure 3. Waiting for the grătar (barbecue). Example of hybrid practices 
They are usually self-confident of their English language competences (Figure 2) as the majority of these updates were written by Translation and Interpreting students, according to my data. Less proficient speakers of English or Romanian might not use languages other than their L1 to update their Facebook profiles although they would display the "complexities in their repertoire" (CsernicskóLaihonen 2016: 27) and include code-switching or language mixing in their online language practices at some point, mostly because the spread of English is a major sign of globalization, and English is a language of high prestige.

Updates are also used as possibilities for hybrid linguistic practices due to the bilingual/multilingual repertoire of the user with an obvious intention to entertain the audience by mixing the languages. Figure 3 presents an example of mixing Romanian and English, where the grătar 'barbecue' term is a very specific word choice, offering more denotations for the Romanian and Hungarian audience than the English word.

These updates may provoke comments and particular keywords, like the Romanian grătar 'barbecue' in the above update text called for a comment in Romanian.

\section{B. Captions}

Captions are short, meaningful statements or quotes which accompany photos, cover photos, pictures, timeline posts, and re-posts and may initiate comments on their own. Language choice for these depends on the content of the post, for example, and on the imagined audience. Sharing quotes (Figure 4) is a very popular trend among users on Facebook, and the use of English adds complexity to their linguistic identity.

They can prompt a variety of language choices and strategies depending on the linguistic repertoire of the participants. Code-switching to Romanian, as my participants explained, is used to reach out to the Romanian friends, or the user chooses Romanian wishing to be understood by the majority of the population in their country, as expressed by one of the interview participants: "It is the state language, right?" As balanced bilinguals, they consider it as an element of their linguistic identity.

The user's choice of languages (Figure 5) reflects their bilingual identity and also their ability to shuttle between these languages. There is no need for translation of the caption: De ce mergeai cu $180 \mathrm{KM} / \mathrm{H}$ ? - Că nu poate mai mult motorul 'Why were you speeding at 100 miles per hour? Because that's all this car is capable of'; the user is aware that the audience will understand the message. However, the Hungarian exclamation: Átüt! 'It comes through' suggests that code-switching is an accepted way to share subtle linguistic phenomena with the audience. 


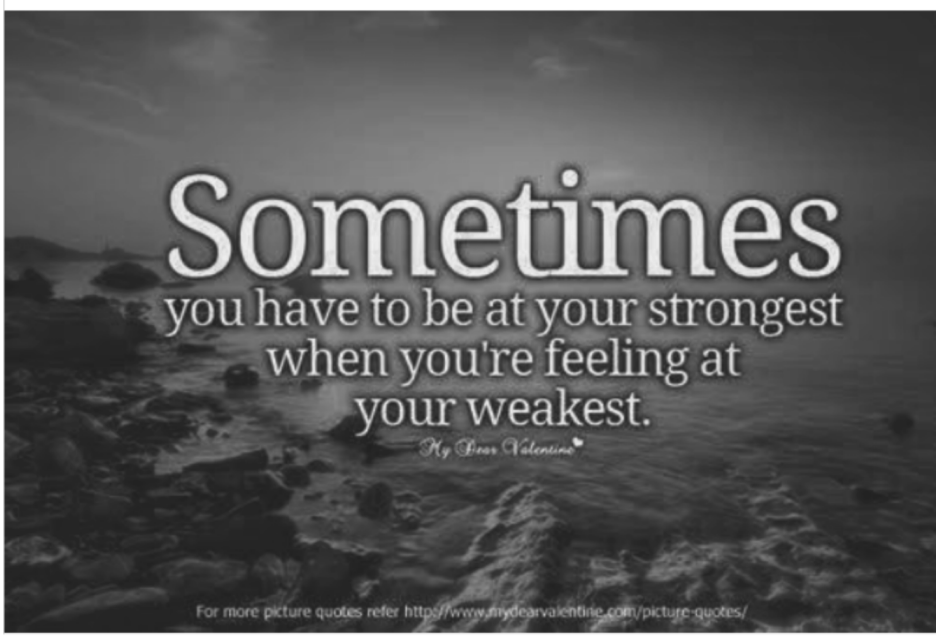

Figure 4. Updated cover photo with an English caption

Átüt!

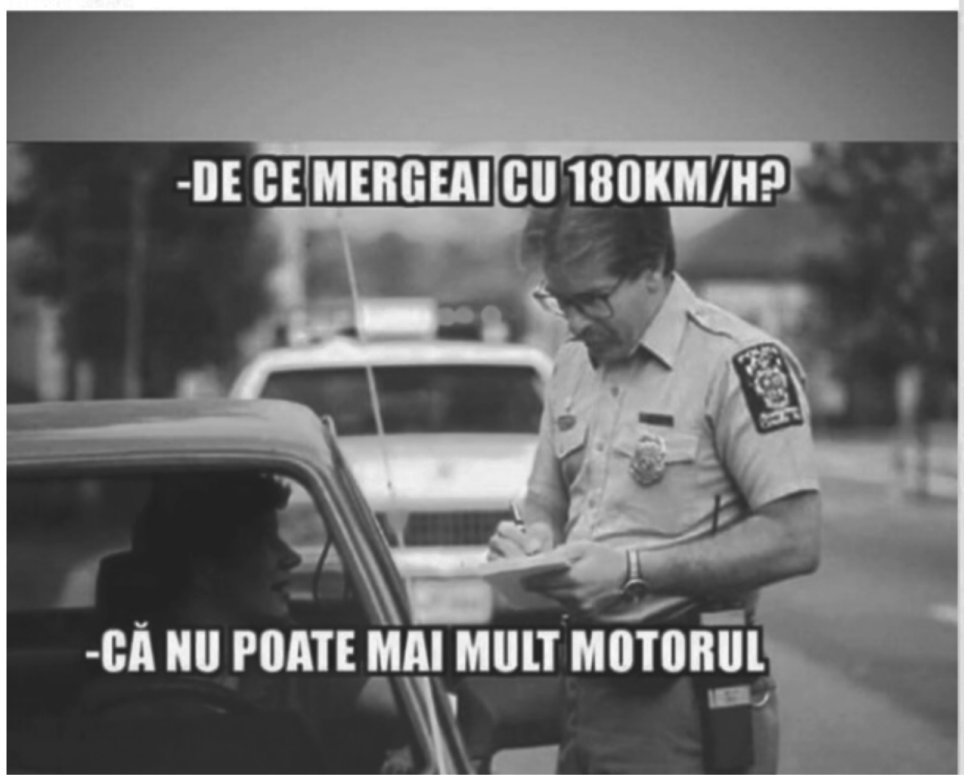

Figure 5. Timeline re-post of a joke with a Romanian caption accompanied by a Hungarian text above 


\section{Comments}

The linguistic repertoire of the user sets the possibilities of language choice, although mixing languages and code-switching mainly depends on the peergroup preferences. It is trendy to switch from one language to another or engage in long discourses in a language which is not the L1 of the speaker.

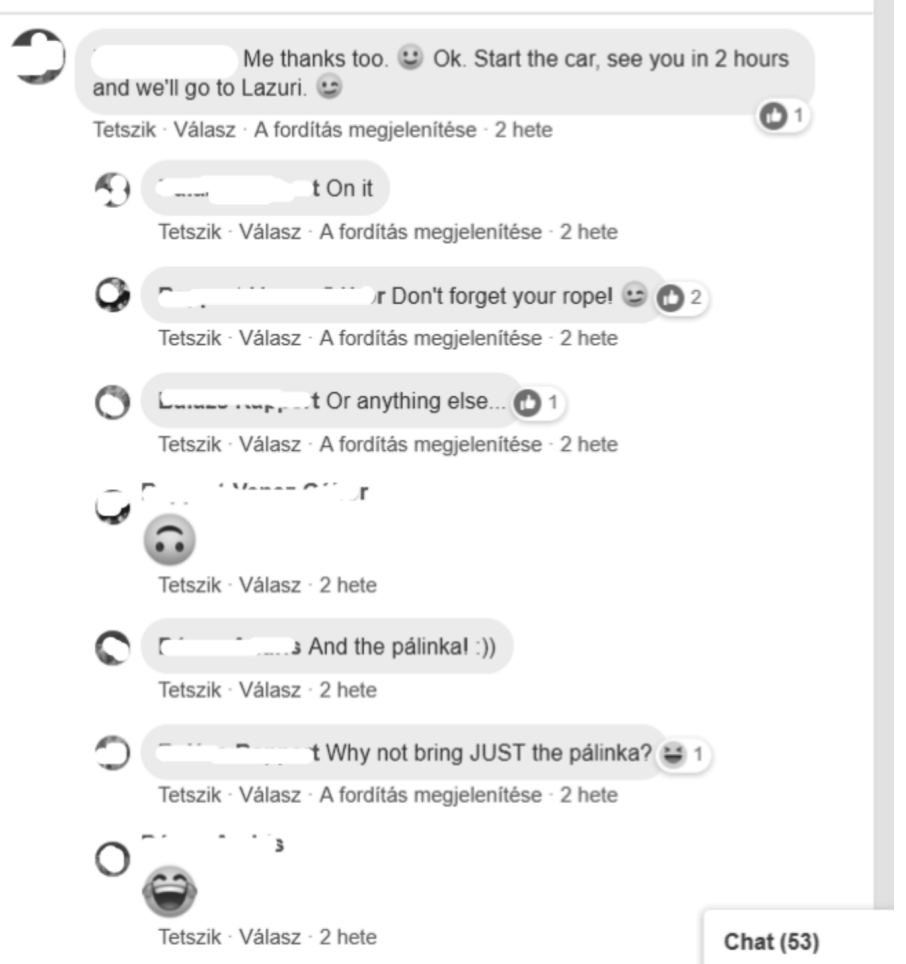

Figure 6. Comments of Hungarian dominant bilinguals written in English

Group preferences in this case (Figure 6 ) reflect the multilingual repertoire of the members of that group of friends, and they deliberately wish to show off and identify themselves as members of the globalized, English-speaking digital space. Figure 6 presents an example of a long line of comments, all written by Hungarian dominant bilinguals. The only word they use in Hungarian is a particular term, pálinka 'brandy', which cannot be translated per se and is therefore used in its original form.

An example of multilingual repertoire is shown in Figure 7, where a balanced (Hungarian-Romanian) bilingual re-posts a video with a French caption (also translates it into English), and comments follow either in English, Romanian, or Hungarian, creating a multilingual discourse. 


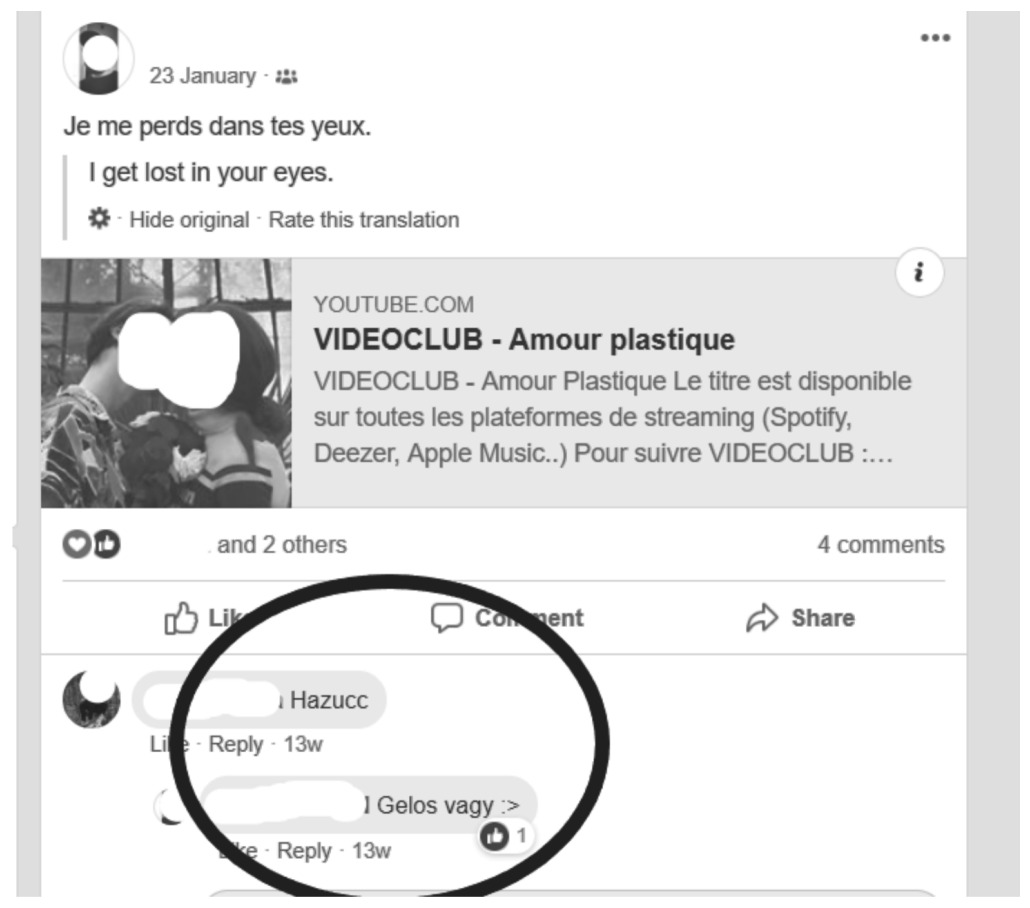

Figure 7. Multilingual repertoire and comments

The user employs hybrid practices, mixing languages within the same comment by replying to a Hungarian comment Hazucc 'You are lying' with the comment where the mix of two languages (Romanian and Hungarian) appears: Gelos vagy 'You are jealous'. The incorrect Hungarian spelling may ease communication and indicate group membership. The created statement, Gelos vagy, is a combination of the Romanian "jealous" and the Hungarian "you are". The user creatively combines the two languages, replying to the Hungarian comment in the same language (Hungarian) but mixing it with Romanian, with the language the user also identifies with. The language of the original content usually calls for the use of the same language in the case of users with a multilingual repertoire, while users with inadequate Romanian or English language proficiency will opt for monolingual, L1 captions and will prefer re-posts in their L1.

Mixing languages and creating hybrid practices within comments or messages is mostly because of fun-making, and it resembles the multilingual talk in everyday student life. A typical example was shared by a participant: Cetateaban vagyok, imediat on my way 'I'm in the castle, on my way immediately', where the mix of Romanian (cetatea/imediat), Hungarian (vagyok), and English (on my way) expresses self-fashioning while constructing multilingual identity in the globalized world. 


\section{Hashtags and quotes}

Quite often, users intertextually mobilize well-known quotes and use them in their posts or borrow hashtags from Instagram.

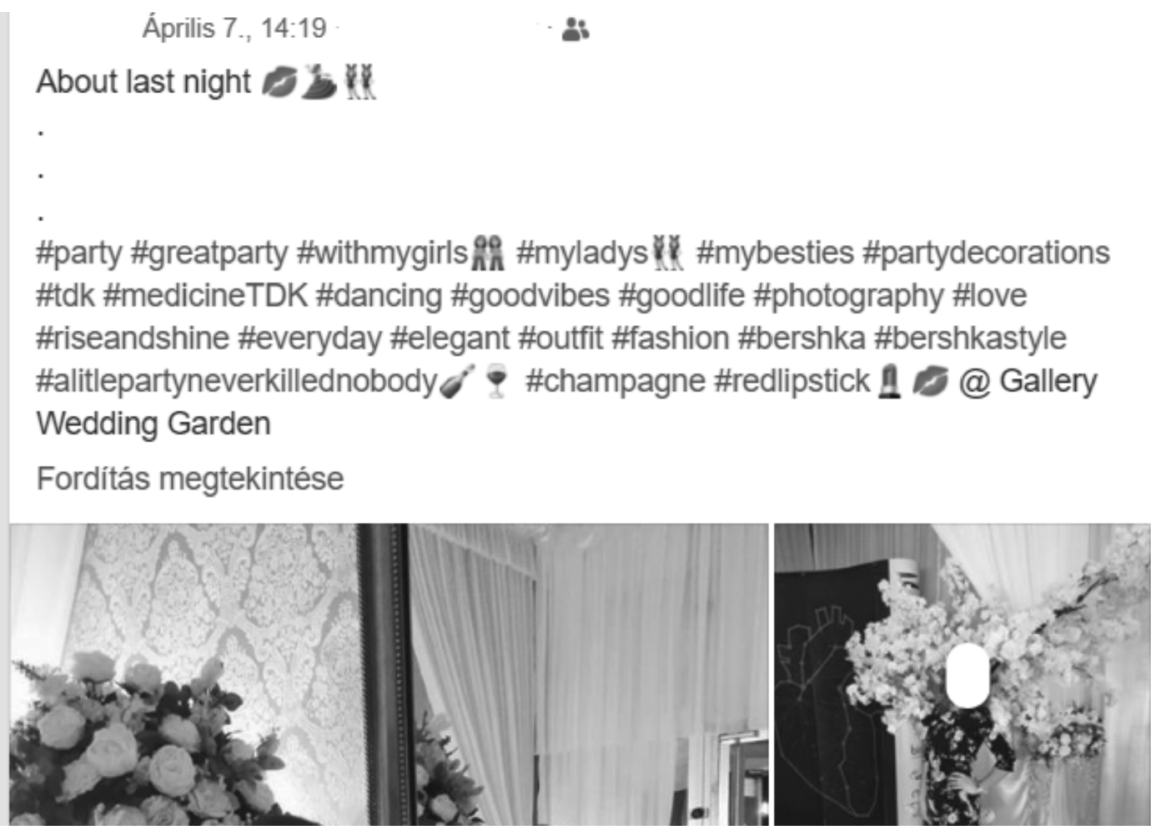

Figure 8. Example of intertextuality in hashtags

These original English posts and hashtags are used to highlight messages, to hunt for followers and likes, or to construct a multilingual identity as well. Romanian is generally used neither by bilinguals with a multilingual repertoire nor by those users who prefer a more monolingual Facebook profile. Codeswitching to English is used for reaching out to a global audience or to inform the audience. Practising English by using hashtags and quotes is still an option, as interview participants revealed. One of the hashtags here (Figure 8) is an example of intertextuality: "alittlepartyneverkillednobody", ${ }^{5}$ referring to a well-known song by the audience. However, the most important reason of using English is still self-fashioning or the display of personal identity. English is viewed as a world language, being a prestigious one, and, by using it, users may adapt their identities to globalized expectations with "a repertoire that is fundamentally hybridized” (Csernicskó and Laihonen 2016: 27). 


\section{Conclusions}

As the digital space has shaped language practices, it has also afforded new opportunities to construct and represent online identities. Online multilingual practices rely on the speaker's complete language repertoire, but they do not necessarily depend on language proficiency, especially in the case of re-posting, using hashtags, quotes, captions with photos, etc. Facebook users build upon their multilingual repertoires in a flexible way, shaped by the linguistic needs of the target audience for the given post or comment. Multilingualism in digital space has become normative for minority student online interaction. As language marks the identity, online users' linguistic identity means associating themselves with a specific language. Users with multilingual repertoire construct their linguistic identities by associating themselves with multiple languages; and the particular language choice depends on the call of the targeted audience as well as on identity construction need at a particular moment in the digital space.

Bilingual student users of Facebook construct their linguistic identities with the help of code-switching and mixing languages in various hybrid practices. Broader linguistic repertoire fosters the possibility to build multilingual or hybrid identity online although self-fashioning and the targeted audience seem more important than real linguistic needs. Language choice and practices in comments, captions, status updates, etc. mark the language status and clearly delineate particular languages. These online linguistic identities cannot be separated from the offline, ethnic linguistic identity of the users. Conflicting linguistic identities in the case of minority speakers can be resolved only if they draw upon their linguistic repertoire and construct a multilingual identity online.

The study presented in this paper raises a number of questions. While this approach provides a rich source of data, the relationship between offline and online linguistic identities of bilingual speakers should be more accurately investigated. Moreover, in order to gain a deeper insight into the complexity of language choices and practices online, focus group discussions should concentrate on participants' particular online practices which would provide more precise metalinguistic data to the research. Finally, examining captions of photos and the use of symbols in the social media would add further important details to the study of digital linguistic practices, e.g. the digital linguistic landscape. 


\section{References}

Androutsopoulos, Jannis. 2013. Online data collection. In Christine MallinsonBecky Childs and Gerard Van Herk (eds), Data Collection in Sociolinguistics: Methods and Application, 236-250. London: Routledge.

- 2015. Networked multilingualism: Some language practices on Facebook and their implications. International Journal of Bilingualism 19(2): 185-205.

Barton, David-Carmen Lee. 2013. Language Online: Investigating Digital Texts and Practices. Abingdon: Routledge.

Blommaert, Jan. 2016. From mobility to complexity in sociolinguistic theory and method. In Nicolas Coupland (ed.), Sociolinguistics: Theoretical Debates, 242262. Cambridge: Cambridge University Press.

Busch, Brigitta. 2012. The Linguistic Repertoire Revisited. Applied Linguistics 33(5): 503-523.

Canagarajah, Suresh. 2011. Codemeshing in academic writing: Identifying teachable strategies of translanguaging. The Modern Language Journal 95(3): 401-417.

- 2013. Negotiating translingual literacy: An enactment. Research in the Teaching of English 48(1): 40-67.

Csernicskó, István-Petteri Laihonen. 2016. Hybrid practices meet nationstate language policies: Transcarpathia in the twentieth century and today. Multilingua 35(1): 1-30.

Darvin, Ron. 2016. Language and identity in the digital age. In Siân Preece (ed.), Handbook of Language and Identity, 523-540. Oxon: Routledge.

Gorter, Durk-Cenoz, Jason. 2017. Language education policy and multilingual assessment. Language and Education 31(3): 231-248.

Greenblatt, Stephen. 1980. Renaissance Self-Fashioning: From More to Shakespeare. Chicago: University of Chicago Press.

Hall, Chira-Chad Nilep. 2015. Code-switching, identity, and globalization. In Deborah Tannen-Heidi Hamilton-Deborah Schiffrin (eds), Handbook of Discourse Analysis, $2^{\text {nd }}$ edition, 597-619. Malden, MA: Blackwell.

Hayes, Marie-Katerine van Stolk-Cooke-Fred Muench. 2015. Understanding Facebook use and the psychological effects of use across generations. Computers in Human Behavior 49: 507-511.

Lange, Patricia. 2017. Publicly private and privately public: Social networking on YouTube. Journal of Computer Mediated Communication 13(1): 361-380.

Lanstyák István. 2011. A nyelvi ideológiák néhány általános kérdéséről [On some general aspects of linguistic ideologies]. In Misad, Katalin-Csehy, Zoltán (eds), Nova Posoniensia (A pozsonyi Magyar tanszék évkönyve) [The Almanac of the Hungarian Department of Bratislava], 13-57. Pozsony: Szenczi Molnár Albert Egyesület-Kalligram Kiadó. 
Lenihan, Aoife-Kelly-Holmes, Helen. 2017. Virtual ethnographic approaches to researching multilingualism online. In Marilyn Martin-Jones-Deidre Martin (eds), Researching Multilingualism: Critical and Ethnographic Approaches, 172-185. London and New York: Routledge.

Li, Wei. 2016. New Chinglish and the post-multilingualism challenge: Translanguaging ELF in China. Journal of English as a Lingua Franca 5(1): $1-26$.

McCrindle, Marc-Emily Wolfinger. 2009. The ABC of XYZ. Understanding the Global Generations, 1-22. UNSW Press.

Schreiber, Brooke. 2015. "I am what I am": Multilingual identity and digital translanguaging. Language Learning and Technology 19(3): 69-87.

Skutnabb-Kangas, Tove-Teresa McCarty. 2008. Key concepts in bilingual education: Ideological, historical, epistemological, and empirical foundations. In Jim Cummins-Nancy Hornberger (eds), Language Policy and Political Issues in Education, Vol. 1, Encyclopedia of Language and Education, $2^{\text {nd }}$ edition, 3-17. New York: Springer. 